\title{
Formal Credit and its Impact on Income - Evidence from the Poor Households in Vietnam
}

\author{
${ }^{1}$ Le Trung Hieu and ${ }^{2}$ Pham Tien Thanh \\ ${ }^{1}$ Department of Finance and Banking, School of Economics and Law, Tra Vinh University, \\ No. 126 Nguyen Thien Thanh Street, Ward 5, Tra Vinh City, Tra Vinh Province, Vietnam \\ ${ }^{2}$ Department of Economics, Faculty of Business Administration, Ton Duc Thang University, \\ No. 19 Nguyen Huu Tho, Tan Phong Ward, District 7, Hochiminh City, Vietnam
}

\author{
Article history \\ Received: 24-06-2017 \\ Revised: 11-07-2017 \\ Accepted: 19-07-2017 \\ Corresponding Author: \\ Pham Tien Thanh \\ Department of Economics, \\ Faculty of Business \\ Administration, Ton Duc Thang \\ University, No. 19 Nguyen Huu \\ Tho, Tan Phong Ward, District \\ 7, Hochiminh City, Vietnam \\ Email: phamtienthanh@tdt.edu.vn \\ thanh.pt@vnp.edu.vn
}

\begin{abstract}
The poor households are normally financial constrained, which inhibits them from income-generating activities. Formal credit market in Vietnam has been more and more improved and thus the poor households can be more accessible to formal sources. Thenceforth, they can relax their financial constraint and then invest in on-farm or off-farm activities to generate income and escape poverty in longer run. This research is aimed at examining the impact of formal credit on income of the poor households in rural Tra Vinh, one of the poorest provinces in Vietnam. The research applies the data from a survey of 381 rural poor and Propensity Score Matching (PSM) method for quantitative analysis. The estimated results find that formal credit borrowers benefit from self-employment activity rather than other income-generating activities. In particular, borrowers from formal sources have significantly higher self-employment income than nonborrowers, but there is no significantly different among them in terms of income from agriculture and wage sources.
\end{abstract}

Keyword: Formal Credit, Impact Evaluation, Income Source Diversification, PSM

\section{Introduction}

Over the past years, formal credit has played a significant role in the agriculture and rural development in Vietnam. The percentage of poor households has declined and the living standard of the rural household has been improved remarkably. The number of Financial Institutions (FIs) involved in rural financial market has been increasing rapidly.

The poor households normally face financial constraint, which thereby inhibit them from investment in income-generating activities (on-farm or off-farm). Many researches find that credit may relax financial constraint via providing the poor with a source of capital for production or business activities. Evidence from empirical studies documents that credit significantly increases income of the poor households (Morduch and Haley, 2001; Barslund and Tarp, 2008). However, some studies argue that rural credit does not have the effect on income improvement in short term (Takahashi et al., 2010). Some even state that credit may push the borrowers into cycles of debt, increase workloads and cause violence or harassment in the family (Copestake et al., 2001; Morduch, 1998; Ganle et al., 2015).
It has been reported from empirical studies in Vietnam that credit significantly enhances households income, consumption or self-employment profits, improves accessibility to clean water and better sanitary system and contribute to the poverty reduction (Nguyen, 2008; Lensink and Pham, 2012; Reis and Mollinga, 2012; Phan et al., 2014). Meanwhile, a research by Nghiem et al. (2012) concludes that credit has no significant effect on household income and consumption. However, neither of these studies investigates the role of credit in improving different income sources.

This research is aimed at examining the impact of formal credit on rural households' earned income. Since households may choose to invest in one or more major activities to optimize their return, it is essential and interesting to observe the impact of formal credit on subcategories of earned income including agriculture, wage and self-employment. The quantitative analysis employs propensity score matching method using data from a survey of 383 households in Tra Vinh province. The findings show that formal credit only improves income from self-employment activities while there is no evidence to conclude the role of formal credit in improving income from agricultural and wage activities. 


\section{Literature Review}

Rural financial market in Vietnam co-exists three sectors: informal, formal and semi-formal (Duong and Izumida, 2002). Formal credit in Vietnam is provided mainly through the Vietnam Bank for Agriculture and Rural Development (VBARD) and Vietnam Bank for Social Policies (VBSP). These two banks aim at agriculture and rural development and poverty reduction. Formal credit is essential for agricultural development because it not only gives solution to the failures of rural financial markets, but also is an important factor in promoting production and generating income (Atieno, 1997; Barslund and Tarp, 2008).

With access to credit, the poor can increase their investment in production and thereby they may increase income, improve well-being and escape poverty sustainably (Morduch and Haley, 2001; Khandker, 2005). Madajewicz (2003) finds that lending to the poor helps them to start their own small business and then increase their opportunity of escaping poverty. Liverpool and Winter-Nelson (2010) examine the impact of formal microfinance on various outcomes and find its significantly positive effect on asset accumulation, but no impact on facilitating technologies adoption and consumption growth among the poorest households. Goetz and Gupta (1996) reveal that credit may create leadership opportunities and contribute to reduction of gender inequality.

In Vietnam, a body of empirical studies reveal that credit has significant and positive effect on household income and consumption or self-employment profits, thereby contributing to the poverty reduction (Nguyen, 2008; Lensink and Pham, 2012; Phan et al., 2014; Duong and Thanh, 2015). Regarding non-financial outcomes, credit is also found to improve rural households' accessibility to clean water and modern toilet system (Reis and Mollinga, 2012) or empower women borrowers and enhance gender equality (Dineen and Le, 2015). However, Nghiem et al. (2012) argue that credit, specifically microcredit, has no significant effect on household welfare, measured by income and consumption.

It is summarized from literature that formal credit may improve the rural households' well-being via two main mechanisms. Firstly, the borrowers may use their loan for direct consumption, which may only improve their well-being in short term and in some extreme cases push them deeper into debts due to their less capacity of repayment. Secondly, the borrowers would use credit for income-generating activities, which may enhance their living standard in longer term and help them to escape poverty sustainably. Due to data unavailability, in this research, we only investigates the economic impact of formal credit on welfare, proxied by earned income and its sub-categories including agriculture, self-employment and wage.

\section{Research Methodology}

\section{Estimation Strategy}

In this research, we aim at estimating the average impact of formal credit program on the households that actually borrow from such programs. To find an answer to this issue, we employ the counterfactual approach of causality (Heckman et al., 1997). In a randomized experimental design, the Average impact of a Treatment on the Treated (ATT) is the difference between mean values of the outcome for the treatment (borrowing) and control (non-borrowing) groups. However, since borrowing status is non-random but self-selected in our present sample, we cannot follow this approach. In such setting, a non-experimental method is suggested to evaluate the impact (Smith and Todd, 2005; Caliendo and Kopeinig, 2008).

The Average Treatment effect on the Treated (ATT) is expressed as follows:

$$
\begin{aligned}
& A T T=E\left(Y_{1 i}-Y_{0 i} \mid C R_{i}=1\right) \\
& =E\left(Y_{1 i} \mid C R_{i}=1\right)-E\left(Y_{0 i} \mid C R_{i}=1\right)
\end{aligned}
$$

where, $Y_{1 i}$ denotes the outcome of household $i$ borrowing from formal credit sources, $Y_{0 i}$ denotes the outcome of the same household without borrowing from such sources. $C R_{i}$ is the borrowing status, equal to 1 if the household borrows from formal credit sources and 0 otherwise. Literature on impact evaluation defines borrowers as treatment group and non-borrowers as control group. However, we cannot observe an individual household $i$ at both stages. In other words, we cannot observe the outcome of formal credit borrowers if they had not borrowed and vice versa. In literature of impact evaluation, this is called counterfactual. Therefore, a major challenge in impact evaluation of a credit program is to find a suitable counterfactual from the non-borrowers of formal sources.

The selection of an appropriate non-experimental method depends on data availability (Smith and Todd, 2005). Therefore, PSM would be more suitable in our study since the data is cross-sectional (Rosenbaum and Rubin, 1983). PSM initiated and was developed by Rosenbaum and Rubin (1983); Becker and Ichino (2002) and Khandker et al. (2010). PSM can be applied to reduce the selection bias and construct an appropriate counterfactual from the control group on the basis of observable characteristics. That is, PSM will attempt to find non-borrowers who are most similar to borrowers regarding the observable characteristics and then match them to compare the difference in outcomes. The first step of PSM is to estimate the probability of access to formal credit. The estimated equation is as follows: 


$$
P\left(X_{i}\right)=\operatorname{Prob}\left(C r_{i}=1 \mid X_{i}\right)=E\left(C r_{i} \mid X_{i}\right)
$$

where, $C r_{\mathrm{i}}$ represents borrowing status of household $i(1)$ if households borrow from formal sources; and 0 otherwise); $X_{i}$ denote variables that affect households' access to formal credit. From this equation, we can estimate the probability of access to credit or propensity score of each household. Based on the previous empirical studies by Yinger (1998; Duong and Izumida, 2002; Li et al., 2011; Khoi et al., 2013), this research includes in the model the factors presented in Table 1. In the next step, the common support region will be determined; that is, some observations may be dropped out due to their too different characteristics (propensity score). Then, the balancing property would be tested. Specifically, this testing process is conducted via categorizing the observations into blocks based on their propensity scores (Dehejia and Wahba, 2002). This is considered as re-randomization process that may reduce selection bias.

Then, each treatment unit will be matched with one or some control units based on their most similar propensity score using various techquiques. Then, the difference in outcomes between each treated unit and control units are calculated. This difference is considered as "individual gain". Finally, mean of all individual gains will be computed to capture the average impact of formal credit program. Average Treatment effect on the Treated (ATT) using PSM is expressed using the following function:

$$
\begin{aligned}
& A T T=E\left(Y_{1 i}-Y_{0 i} \mid P\left(X_{i}\right), C R_{i}=1\right) \\
& =E\left(Y_{1 i} \mid P\left(X_{i}\right), C R_{i}=1\right)-E\left(Y_{0 i} \mid P\left(X_{i}\right), C R_{i}=1\right)
\end{aligned}
$$

In order to check the robustness of the results, we apply alternative matching techniques such as Nearestneighbor, Radius and Kernel. Moreover, for correct estimation of standard errors, bootstrapping estimates should be employed (Khandker et al., 2010).

\section{Selection of Variables}

Treatment variable is the borrowing status of households. This variable will receive a value of 1 if households borrow from any formal sources and 0 if otherwise. In addition to credit variable, the explanatory variables used for predicting borrowing status or calculating propensity score are presented in the upper part of Table 1. These variables are selected on the basis of previous empirical studies (Yinger, 1998; Duong and Izumida, 2002; Li et al., 2011; Khoi et al., 2013; Duong and Thanh, 2015). The outcome variables arealso shown in the bottom part of Table 1.

\section{Data and Summary Statistics}

The survey is conducted in Tra Vinh, one of the poorest provinces in the Mekong Delta River in Vietnam, where agricultural activities play a dominant role, accounting for $39 \%$ of the province's economy. The rural households in Tra Vinh depend heavily on crops, livestock and aquaculture. Similar to other provinces in the region, Tra Vinh is also vulnerable to natural disaster, which thereby has inverse effect on the province's agricultural production activities.

The province has the total population of 1.1 million, of which $32 \%$ are Khmer minority ethnic. The poor households account for 11.16 per cent of the population, while among the Khmer ethnic group, the poor account for around $20.46 \%$. Most of the poor and the Khmer ethnic group reside in rural areas of Tra Vinh. Since our research of interest is to investigate whether formal credit can improve the living standard of the poor in general and the Khmer ethnic poor in particular, we randomly selected 381 poor households in rural area for quantitative analysis.

In recent years, Tra Vinh has gained many important achievements. The rural financial market has been gradually improved and better organized. More households can have access to credit from formal sources. However, there is lack of empirical studies on the impact of formal credit on living standard of the rural poor in Tra Vinh, where there is a high proportion of the Khmer ethnic group.

The research uses the primary data from a survey of 381 poor households in Tra Vinh province. Table 2 reports some statistical summary on loans obtained by households. Among 381 households in the sample, 180 households can access to formal credit sources such as bank or mass organizations. Meanwhile, 16 households are found to borrow from informal sources such as friends, relatives and so forth. There are 194 households obtaining loan from at least one source and 2 households borrowing from both sources.

The average loan size from formal sources is around 13.2 million VND and informal loan size is, on average, around 18.4 million VND. The last column of Table 2 indicates the important role of formal loans. Though the average loan size is not large, formal loans still account for around $74.1 \%$ of the total income.

The purpose of this research is to investigate the impact of formal credit. Thenceforth, in this research, treatment group are defined as borrower from formal sources (180 observations) and control group include borrowers from informal sources or non-borrowers (201 observations). Table 3 presents the summary statistics of the research sample. 
Table 1. Variable used for analysis

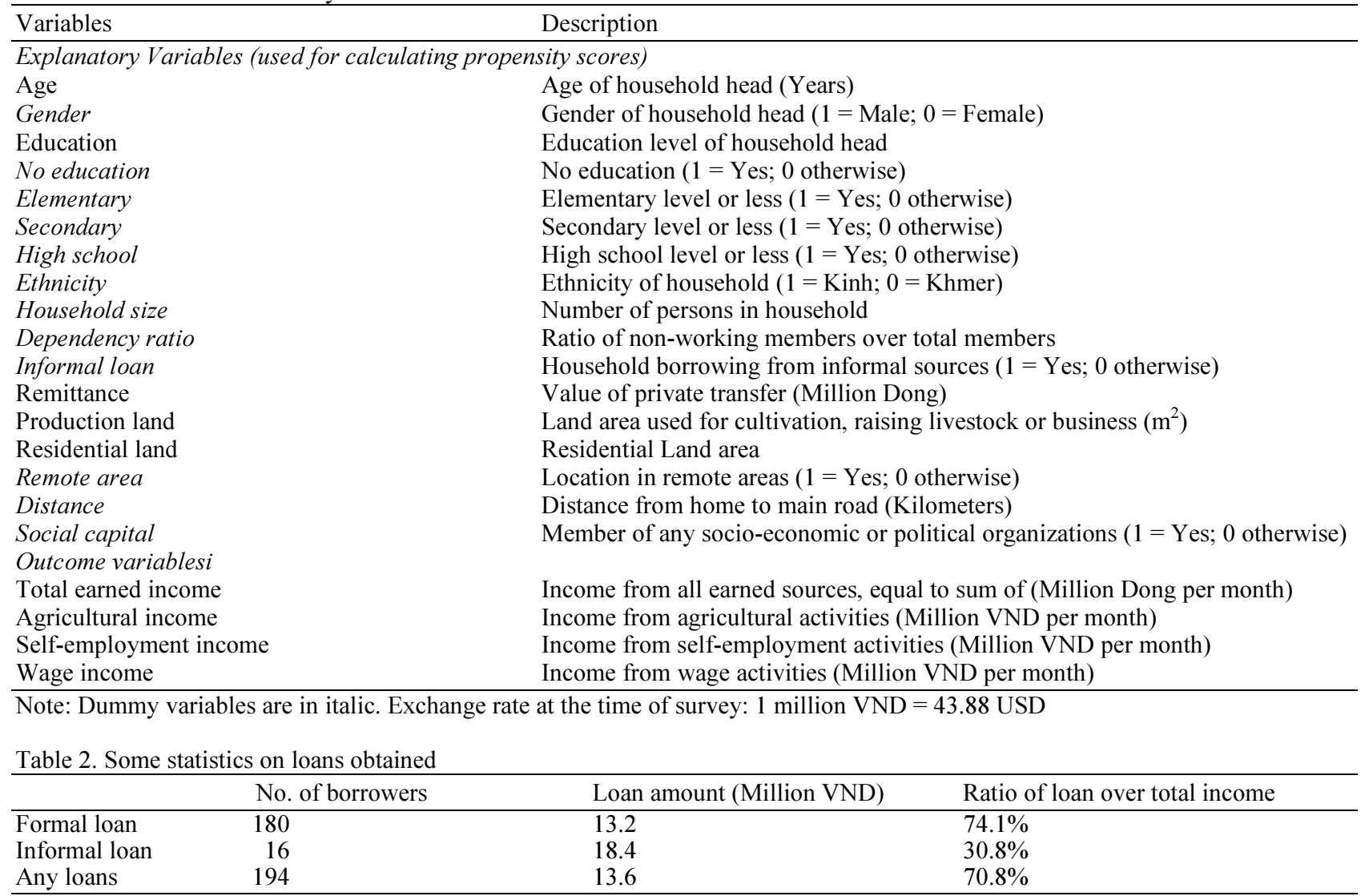

Source: Authors' calculation using the survey data. Note: Exchange rate at the time of survey: 1 million VND $=43.88$ USD

Table 3. Descriptive statistics

\begin{tabular}{|c|c|c|c|c|c|c|}
\hline \multirow[b]{2}{*}{ Variable } & \multicolumn{2}{|l|}{ Total } & \multicolumn{2}{|c|}{ Borrowers } & \multicolumn{2}{|c|}{ Non-Borrowers } \\
\hline & Mean & Std. Dev. & Mean & Std. Dev. & Mean & Std. Dev. \\
\hline \multicolumn{7}{|c|}{ Explanatory Variables (used for calculating propensity scores) } \\
\hline Age & 52.180 & 13.250 & 51.11 & 12.340 & 53.140 & 13.970 \\
\hline Gender & 0.661 & 0.474 & 0.700 & 0.460 & 0.627 & 0.485 \\
\hline \multicolumn{7}{|l|}{ Education level } \\
\hline No education & 0.297 & 0.457 & 0.239 & 0.428 & 0.348 & 0.478 \\
\hline Elementary & 0.396 & 0.490 & 0.444 & 0.498 & 0.353 & 0.479 \\
\hline Secondary & 0.215 & 0.412 & 0.233 & 0.424 & 0.199 & 0.400 \\
\hline High school & 0.092 & 0.289 & 0.083 & 0.277 & 0.100 & 0.300 \\
\hline Ethnicity & 0.703 & 0.457 & 0.672 & 0.471 & 0.731 & 0.444 \\
\hline Household size & 3.940 & 1.530 & 4.106 & 1.504 & 3.791 & 1.541 \\
\hline Dependency ratio & 0.393 & 0.257 & 0.380 & 0.267 & 0.404 & 0.248 \\
\hline Informal loan & 0.042 & 0.201 & 0.011 & 0.105 & 0.070 & 0.255 \\
\hline Remittance & 2.170 & 7.490 & 1.540 & 4.960 & 2.730 & 9.160 \\
\hline Production land & 1046.160 & 1530.720 & 1157.010 & 1473.770 & 946.890 & 1577.010 \\
\hline Residential land & 226.510 & 301.060 & 209.430 & 272.330 & 241.800 & 324.560 \\
\hline Remote area & 0.199 & 0.400 & 0.189 & 0.393 & 0.209 & 0.408 \\
\hline Distance & 0.807 & 0.798 & 0.725 & 0.741 & 0.880 & 0.842 \\
\hline Social capital & 0.100 & 0.300 & 0.133 & 0.341 & 0.070 & 0.255 \\
\hline \multicolumn{7}{|l|}{ Outcome variables } \\
\hline Total income & 4.25 & 8.44 & 5.28 & 10.97 & 3.34 & 5.09 \\
\hline Agricultural income & 1.08 & 1.93 & 0.91 & 1.42 & 1.24 & 2.28 \\
\hline Self-employment income & 1.68 & 8.31 & 2.86 & 10.98 & 0.62 & 4.57 \\
\hline Wage income & 1.49 & 1.65 & 1.50 & 1.67 & 1.48 & 1.63 \\
\hline Obs & 381.00 & & 180.00 & & 201.00 & \\
\hline
\end{tabular}

Note: Dummy variables are in italic; Exchange rate at the time of survey: 1 Million VND $=43.88$ USD 


\section{Results and Discussion}

Table 4 presents the estimated results from Probit model. Based on this result, propensity score of each household will be calculated. Percentage of Correctness Prediction is $64.04 \%$, which indicates that the independent variables explain the accessibility to credit quite well. VIF values show that the explanatory variables in Probit model are not correlated and thus there is no multi-co linearity. There are 371 households falling into common support region and 10 households out of this region. For visual inspection, Fig. 1 shows the density distribution of propensity scores for treated group (borrowers) and untreated group (non-borrower) by common support. The figure indicates that that there are sufficient common support region for matching. It is also reported in Table 4 that the balancing property is satisfied in our data, which means there is no statistically significant difference regarding observable characteristics between borrowers and non-borrowers after matching.

Table 5 reveals that formal credit has no significant impact on total income from earned sources including agriculture, self-employment and wage. The finding is similar to Takahashi et al. (2010) who conclude no significant impact of microcredit on total income.

However, the literature documents that formal credit is not a "magic bullet". That is, credit may be effective in one or some specific activities at disaggregate level but not aggregate level. In other words, rural households may choose to invest in one or more major activities to maximize their utility. Thenceforth, it is essential to examine the economic impacts of formal credit on different types of earned income sources such as agriculture, self-employment and wage.

Table 6 shows that formal credit borrowers have higher self-employment income than non-borrowers ranging from 2.10-2.49 million VND and these impacts are statistically significant at 5\%. Table 6 also reveals that there is no evidence to conclude the impact of formal credit on income from agricultural and wage sources.

The results reflect the real situation in the provinces in Mekong Delta River region in the period of 20152016. It is noteworthy that during this period, these provinces were badly stricken by devastating drought and salinity intrusion. The poor are typically vulnerable to such natural shocks due to no or less effective adaptive measures. Therefore, natural disasters normally cause severe consequences on their agricultural production. The decrease in agricultural production may result in enormous negative financial impacts on farmers in drought- and salinity-affected areas. This may be the reason why formal credits have no significant effect on income from agricultural activities.

Another reason is possible that poor households may not use credit effectively when investing in agriculture. Therefore, credit program should be combined with other supplementary programs such as training. Thenceforth, the role of agricultural extension center or farmers union should be promoted. Infrastructure should be also improved to reduce transaction cost or travel cost, to increase accessibility to input and output markets, as well as to mitigate the negative effect of agricultural shocks (natural disaster).

Table 4. Estimated results using probit

\begin{tabular}{llll}
\hline Variable & Coef. & T-Stat & VIF \\
\hline Age & -0.0044 & -0.72 & 1.45 \\
Gender & -0.0157 & -0.10 & 1.36 \\
Education level (High school is based) & & & 3.86 \\
No education & 0.0233 & 0.080 & 3.58 \\
Elementary & 0.3292 & 1.290 & 2.71 \\
Secondary & 0.1664 & 0.630 & 1.11 \\
Ethnicity & -0.2067 & -1.32 & 1.16 \\
Household size & $0.1419^{* * *}$ & 2.960 & 1.07 \\
Dependency ratio & -0.2387 & -0.87 & 1.07 \\
Informal loan & $-1.2857^{* * *}$ & -2.89 & 1.09 \\
Remittance & $-0.0237^{* *}$ & -2.14 & 1.36 \\
Production land & 0.0001 & 1.410 & 1.28 \\
Residential land & $-0.0004^{*}$ & -1.66 & 1.79 \\
Remote area & $-0.4420^{*}$ & -1.89 & 1.10 \\
Distance & $-0.1638^{*}$ & -1.83 & 1.65 \\
Social capital & $0.9400^{* * *}$ & 3.090 & -0.20 \\
Constant & -0.0897 & & \\
Obs & $381(371)^{1}$ & \\
Common support region & {$[0.10828768,0.87808755]$} & & \\
Balancing test & Satisfied & & \\
Max VIF (Mean VIF) & $3.86(1.71)$ & & \\
Percentage of correctness prediction & $64.04 \%$ & & \\
\hline Note: * $* *$ and $* * *$ Significant at 1,5 and $1 \%$, respectively; ${ }^{1}$ In parentheses are the number of OBS falling out of common \\
support region & & &
\end{tabular}


Table 5. Impact of formal credit on total earned income

\section{Total earned income}

\begin{tabular}{ll}
\hline ATT & T-Stat \\
1.75 & 1.41 \\
1.46 & 1.07 \\
1.41 & 1.26 \\
1.84 & 1.47 \\
1.59 & 1.34
\end{tabular}

Matching estimator

$\operatorname{NNM}(\mathrm{n}=1)$

$\operatorname{NNM}(\mathrm{n}=5)$

Radius $($ Caliper $=0.01)$

Radius (Caliper $=0.005$ )

Note: ** and *: Significant at 5 and 10\%, respectively; NNN: Nearest-Neighbor Matching; ATT is estimated using 'psmatch2' command by Leuven and Sianesi (2015). Bootstrap with 50 replications is applied for estimation; Unit: Million VND; Exchange rate at the time of survey: 1 million VND $=43.88$ USD

Table 6. Impact of formal credit on sub-categories of earned income

\begin{tabular}{|c|c|c|c|c|c|c|}
\hline \multirow[b]{2}{*}{ Matching estimator } & \multicolumn{2}{|c|}{ Agriculture } & \multicolumn{2}{|c|}{ Self-employment } & \multicolumn{2}{|c|}{ Wage } \\
\hline & ATT & T-Stat & ATT & T-Stat & ATT & t-stat \\
\hline $\mathrm{NNM}(\mathrm{n}=1)$ & -0.04 & -0.13 & $2.22 * *$ & 2.13 & -0.43 & -1.38 \\
\hline NNM $(n=5)$ & -0.49 & -1.60 & $2.12^{*}$ & 1.83 & -0.17 & -0.86 \\
\hline Radius (Caliper = 0.01) & -0.49 & -1.57 & $2.10 * *$ & -1.99 & -0.20 & -0.98 \\
\hline Radius $($ Caliper $=0.005)$ & -0.41 & -1.26 & $2.49 * *$ & 2.41 & -0.25 & -0.95 \\
\hline Kernel $($ Bandwidth $=0.01)$ & -0.46 & -1.58 & $2.29 * *$ & 2.36 & -0.23 & -1.15 \\
\hline
\end{tabular}

Note: $* *$ and $*$ : Significant at 5 and 10\%, respectively; NNN: Nearest-Neighbor Matching; ATT is estimated using 'psmatch2' command by Leuven and Sianesi (2015). Bootstrap with 50 replications is applied for estimation; Unit: Million VND; Exchange rate at the time of survey: 1 million VND $=43.88 \mathrm{USD}$

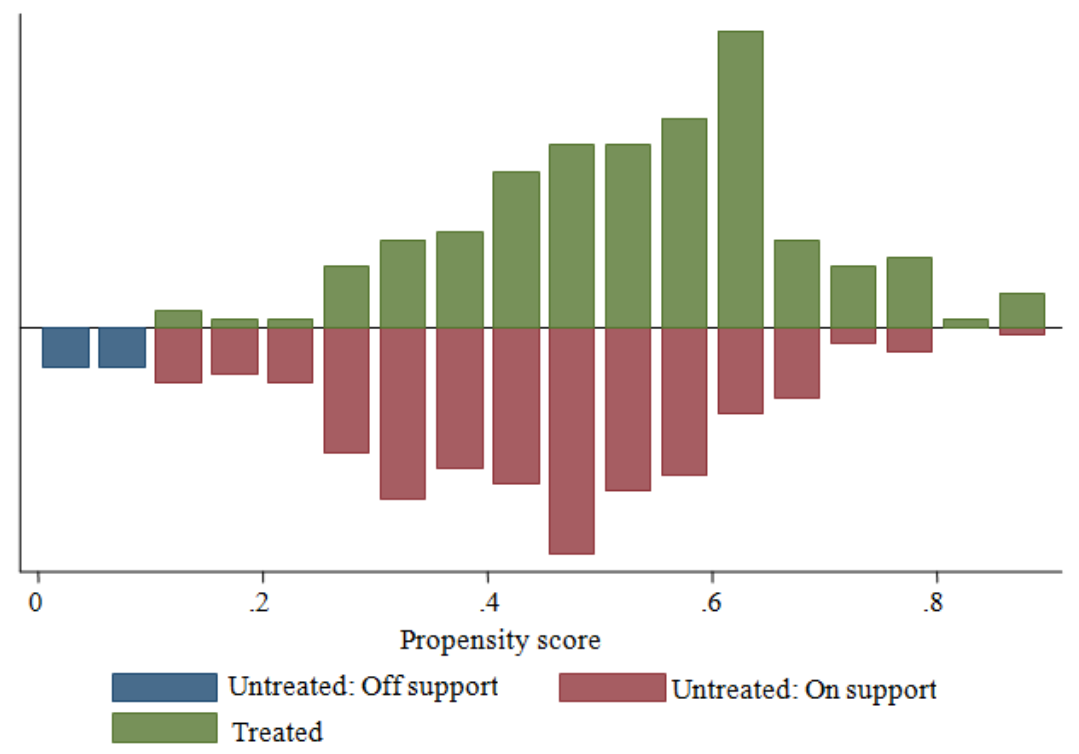

Fig. 1. Distribution of estimated propensity scores by borrowing status

Moreover, Table 2 indicates that the average size of formal loan are quite small at around 13.2 million VND, while investment in agricultural production, especially new technologies (i.e., new inputs, irrigation systems and so forth) normally incur high initial and variable costs. Therefore, the borrowers from formal sources may not use their loan for agricultural production. This may explain why the impact of formal loan on agricultural income is not significant. Moreover, agricultural production activities induce more risks than self- employment; thenceforth, the poor may not use credit to invest in agricultural but self-employment activities.

Regarding wage income, the coefficients are statistically insignificant, which indicates no effect of formal credit on income from this source. The qualitative analysis reveals that most of households use formal credit for agricultural or self-employment activities rather than seeking salaried jobs. This finding is quite similar to other empirical studies about impacts of rural credit. 
The results using PSM heavily depend on the Conditional Independence Assumptions (CIA) and selection on observable covariates, which may still cause potential hidden biases. If there are unobservable covariates that affect both access to formal credit and income at the same time, the matching estimators would be biased and not robust. Another limitation of this research is that we can not observe the change in income of households over time due to data unavailability. A further research should be conducted using panel data with more advanced methods such as Difference-inDifference (DID) and match-DID. Thenceforth, we can reduce the potential estimation bias when using PSM.

\section{Conclusion}

This research investigates the impact of formal credit on income of the poor households in Tra Vinh province. Since the access to credit is not random process but selfselection, this research applies Propensity Score Matching (PSM) to reduce selection bias. The results find that the poor households with formal credit have higher self-employment income than other households. Meanwhile, there is no evidence to conclude that the poor with formal credit would have greater agriculture and wage income than the non-borrowers.

The most possible reason is that in early 2016, the households in Mekong Delta River region were badly hit by a severe natural disaster (drought and saltwater), which thereby had inverse effects on their agricultural production. Another plausible explanation is that investment in agricultural activities may be not effective in short term. Moreover, agricultural activities are riskier than self-employment; thenceforth, the poor would not use credit to invest in agriculture but self-employment activities. Moreover, some households may not use credit effectively when investing in agricultural production. Therefore, it is implied that credit program should be combined with other supplementary programs such as training to improve the effective of credit use. It is thereby implied that the role of agricultural extension center or farmers union should be promoted. Infrastructure should be also improved to reduce transaction cost or travel cost, to increase accessibility to input and output markets, as well as, more importantly, to mitigate the negative effect of agricultural shocks (natural disaster).

This paper only uses cross-sectional data and a quasiexperimental method. Therefore, we can only estimate the economic impacts of formal credit in short term. Moreover, we cannot observe the effect of formal credit on the change in outcomes between two comparison groups across time. A further research using experimental and longitudinal data with more modern method is suggested.

\section{Acknowledgement}

The authors acknowledge the financial support by scientific research fund from Tra Vinh University. We are indebted to anonymous reviewers of the International Conference in Environmental Finance 2017 at Ton Duc Thang University for their comments from which we can improve this paper.

\section{Funding Information}

This research is funded by scientific research fund from Tra Vinh University.

\section{Author's Contributions}

Le Trung Hieu: Building questionnaire, Collecting data, Drafting introduction and literature review and finalizing the manuscript.

Pham Tien Thanh: Analyzing data, interpreting the results and drafting methodology, discussion and conclusion.

\section{Ethics}

The authors confirm that this article is original and unpublished elsewhere. The authors also declare no ethical issues involved.

\section{Conflict of Interest}

The authors declare no potential conflict of interest.

\section{Reference}

Atieno, R., 1997. Determinants of credit demand by smallholder farmers in Kenya: An empirical analysis. Der Tropenlandwirt J. Agric. Trop. Subtrop., 98: 63-71.

Barslund, M. and F. Tarp, 2008. Formal and informal rural credit in four provinces of Vietnam. J. Dev. Stud., 44: 485-503.

Becker, S.O. and A. Ichino, 2002. Estimation of average treatment effects based on propensity scores. Stat. J., 2: 358-377.

Caliendo, M. and S. Kopeinig, 2008. Some practical guidance for the implementation of propensity score matching. J. Econom. Surveys, 22: 31-72.

Copestake, J., S. Bhalotra and S. Johnson, 2001. Assessing the impact of microcredit: A Zambian case study. J. Dev. Stud., 37: 81-100.

Dehejia, R.H. and S. Wahba, 2002. Propensity score matching methods for non- experimental causal studies. Rev. Econom. Stat., 84: 151-161.

Dineen, K. and Q.V. Le, 2015. The impact of an integrated microcredit program on the empowerment of women and gender equality in rural Vietnam. J. Dev. Areas, 49: 23-38. 
Duong, P.B. and Y. Izumida, 2002. Rural development finance in Vietnam: A micro-econometric analysis of household surveys. World Dev., 30: 319-335.

Duong, P.B. and P.T. Thanh, 2015. Impact evaluation of microcredit on welfare of the Vietnamese rural households. Asian Social Sci., 11: 190-190.

Ganle, J.K., K. Afriyie and A.Y. Segbefia, 2015. Microcredit: Empowerment and disempowerment of rural women in Ghana. World Dev., 66: 335-345.

Goetz, A.M. and R.S. Gupta, 1996. Who takes the credit? Gender, power and control over loan use in rural credit programs in Bangladesh. World Dev., 24: 45-63.

Heckman, J.J., H. Hidehiko and P. Todd, 1997. Matching as an econometric evaluation estimator: Evidence from evaluating a job training program. Rev. Econom. Stud., 64: 605-654.

Khandker, S.R., 2005. Microfinance and poverty: Evidence using panel data from Bangladesh. World Bank Econom. Rev., 19: 263-286.

Khandker, S.R., G.B. Koolwal and H.A. Samad, 2010. Handbook on Impact Evaluation: Quantitative Methods and Practices. 1st Edn., World Bank, Washington DC., ISBN-10: 0821380281, pp: 239.

Khoi, P.D., C. Gan, G.V. Nartea and D.A. Cohen, 2013. Formal and informal rural credit in the Mekong river delta of Vietnam: Interaction and accessibility. J. Asian Econom., 26: 1-13.

Lensink, R. and T.T.T. Pham, 2012. The impact of microcredit on self-employment profits in Vietnam. Econom. Transition, 20: 73-111.

Leuven, E. and B. Sianesi, 2015. PSMATCH2: Stata module to perform full Mahalanobis and propensity score matching, common support graphing and covariate imbalance testing. Stat. Software Components.

Li, X., C. Gan and B. Hu, 2011. Accessibility to microcredit by Chinese rural households. J. Asian Econom., 22: 235-246.

Liverpool, L.S.O. and A. Winter-Nelson, 2010. Poverty status and the impact of formal credit on technology use and wellbeing among Ethiopian Smallholders. World Dev., 38: 541-554.
Madajewicz, M., 2003. Does the credit contract matter? The impact of lending programs on poverty in Bangladesh. Proceedings of the Conference, Micro Foundations of Credit Contracts, (FCC' 03), Columbia University, European.

Morduch, J. and B. Haley, 2001. Analysis of the effects of microfinance on poverty reduction. NYU Wagner Working Paper No. 1014.

Morduch, J., 1998. Does Microfinance Really Help the Poor?: New Evidence from Flagship Programs in Bangladesh. 1st Edn., Research Program in Development Studies, Woodrow School of Public and International Affairs, Princeton, NJ.

Nguyen, V.C., 2008. Is a governmental micro-credit program for the poor really pro-poor? Evidence from Vietnam. Dev. Econom., 46: 151-187.

Nghiem, S., T. Coelli and P. Rao, 2012. Assessing the welfare effects of microfinance in Vietnam: Empirical results from a quasi-experimental survey. J. Dev. Stud., 48: 619-632.

Phan, D.K., C. Gan, G.V. Nartea, and D.A. Cohen, 2014. The impact of microcredit on rural households in the Mekong river Delta of Vietnam. J. Asia Pac. Econ., 19: 558-578.

Reis, N. and P.P. Mollinga, 2012. Water supply or 'beautiful latrines'? Microcredit for rural water supply and sanitation in the Mekong Delta, Vietnam. Austrian J. South-East Asian Stud., 5: 10-29.

Rosenbaum, P.R. and D.B. Rubin, 1983. The central role of the propensity score in observational studies for causal effects. Biometrika, 70: 41-55.

Smith, J.A. and P.E. Todd, 2005. Does matching overcome LaLonde's critique of non-experimental estimators? J. Econometr., 125: 305-353.

Takahashi, K., T. Higashikata and K. Tsukada, 2010. The short-term poverty impact of small-scale, collateral-free microcredit in Indonesia: A matching estimator approach. Dev. Econom., 48: 128-155.

Yinger, J., 1998. Evidence on discrimination in consumer markets. J. Econom. Perspectives, 12: 23-40. 